\section{Obesity hypoventilation syndrome: does the current definition need revisiting?}

Obesity hypoventilation syndrome (OHS) has been conventionally (and to some extent arbitrarily) defined by the combination of obesity (body mass index (BMI) $>30 \mathrm{~kg} / \mathrm{m}^{2}$ ), daytime hypercapnia (arterial partial pressure of carbon dioxide $\left(\mathrm{PaCO}_{2}\right) \geq 45 \mathrm{~mm} \mathrm{Hg}$ or $\left.6 \mathrm{kPa}\right)$ during wakefulness, and usually (but not always) the presence of 'sleep disordered breathing', such as obstructive sleep apnoea, rapid eye movement sleep hypoventilation or both. ${ }^{1}$ The survival curve for untreated OHS is significantly reduced compared with the non-obese, ${ }^{2}$ and so early identification and treatment for these patients is likely to be beneficial. Little is currently known about the true prevalence of OHS in ambulatory obese individuals, with estimates range from $0.3-0.4 \%$ of the general population, ${ }^{3}$ to around $30 \%$ of hospitalised patients with a BMI $>35 \mathrm{~kg} / \mathrm{m}^{2} .^{2}$ The combined medical costs associated with treatment of obesity associated diseases are estimated to increase by $\$ 48-66$ billion/year in the USA and by $£ 1 \cdot 9-2$ billion/year in the UK by $2030,{ }^{4}$ making OHS an increasingly common and expensive problem. The American Medical Association recently announced that obesity is now considered a 'disease', a step which may improve patient access to obesity treatments and increase funding into obesity research.

The current definition, based as it is on a single one-off measurement of $\mathrm{PaCO}_{2}$, seems to us to be too restrictive; $\mathrm{PaCO}_{2}$ is not constant and, rather like blood pressure where the white coat effect is well recognised, is subject to a variety of influences. For example, patient anxiety over arterial sampling is likely to 'falsely' lower the $\mathrm{PaCO}_{2}$, and many obese subjects hypoventilate overnight, but are able to return their $\mathrm{PaCO}_{2}$ to within normal levels a short time following awakening. ${ }^{5}$ Calculated arterial standard bicarbonate $\left(\mathrm{HCO}_{3}^{-}\right)$level from a conventional blood gas machine, in the absence of another influence on metabolic acid-base status, is a longer term guide to $24-\mathrm{h}$ ventilation and, in some ways, can be viewed as the ' $\mathrm{HbA} 1 \mathrm{c}$ ' of $\mathrm{CO}_{2}$ levels because it represents the renal retention of $\mathrm{HCO}_{3}^{-}$that occurs in response to hypercapnia. Our combined experience in this area is that there are many patients with significant nocturnal hypoventilation who, during the day, have normal-to-high $\mathrm{PaCO}_{2}$ levels, but have alkalotic (>7.40) $\mathrm{pH}$ values, and thus raised standard $\mathrm{HCO}_{3}^{-}$ (or base excess) levels. Serum venous bicarbonate concentration, which is increased by a currently raised $\mathrm{PaCO}_{2}$ level and any renal compensation, has also previously been described to be a useful screening tool in identifying patients with OHS in a group of obese patients with sleep disordered breathing ${ }^{6}$ and might be used as a simpler alternative for screening.

In our view, the use of $\mathrm{PaCO}_{2}$ alone in the definition of OHS may miss early disease, if used in isolation. Clearly delineating the OHS population is a key issue, for appropriate care, and for conducting unbiased clinical studies and determination of phenotypes associated with poor prognosis within the obese population. We propose that the definition of OHS should be based on obesity, plus a $\mathrm{PaCO}_{2} \geq 45 \mathrm{~mm} \mathrm{Hg}(6 \mathrm{kPa}) \mathrm{OR}$ an arterial base excess $>3 \mathrm{mmol} / \mathrm{L}$ OR a standard $\mathrm{HCO}_{3}^{-}>27 \mathrm{mmol} / \mathrm{L}$ (in the absence of another cause for a metabolic alkalosis). Clearly, the BMI, the exact levels of $\mathrm{PaCO}_{2}$, and now the $\mathrm{HCO}_{3}^{-}$, used in the definition of OHS are relatively arbitrary thresholds, and may benefit from refinement; but the addition of a raised arterial $\mathrm{HCO}_{3}^{-}$criterion seems to add value to the identification of this increasing problem.

Nicholas Hart, ${ }^{1}$ Swapna Mandal, ${ }^{1}$ Ari Manuel, ${ }^{2}$ Babak Mokhlesi, ${ }^{3}$ Jean-Louis Pépin, ${ }^{4}$ Amanda Piper, ${ }^{5}$ John R Stradling ${ }^{6}$ 
${ }^{1}$ Lane Fox Unit and Critical Care, St Thomas' Hospital London, UK

${ }^{2}$ Oriel College, University of Oxford, Oxford, UK

${ }^{3}$ Section of Pulmonary and Critical Care Medicine, University of Chicago Pritzker School of Medicine,

Chicago, Illinois, USA

${ }^{4}$ University Grenoble Alpes, HP2 Laboratory, Grenoble, France; Inserm, U1042, Grenoble University Hospital, Sleep Laboratory and Physiology Department, Grenoble, France

${ }^{5}$ Sleep Unit, Royal Prince Alfred Hospital, Camperdown, New South Wales, Australia

${ }^{6}$ Adult Respiratory Sleep Disorders, Oxford Centre for Respiratory Medicine, Oxford, UK

Correspondence to Dr Ari Manuel, Oriel College, University of Oxford, Oriel Square, Oxford OX1 4EW, UK; ari.manuel@oriel.ox.ac.uk

Contributors NH, SM, AM, BM, J-LP, AP and JRS all prepared, edited and reviewed the manuscript. JRS is the senior author for this submission.

Competing interests None.

Provenance and peer review Not commissioned; internally peer reviewed.

To cite Hart N, Mandal S, Manuel A, et al. Thorax 2014;69:83-84.

Received 2 August 2013

Accepted 5 August 2013

Published Online First 28 August 2013

Thorax 2014;69:83-84.

doi:10.1136/thoraxjnl-2013-204298

\section{REFERENCES}

1 Berger KI, Ayappa I, Chatr-Amontri B, et al. Obesity hypoventilation syndrome as a spectrum of respiratory disturbances during sleep. Chest 2001;120:1231-8.

2 Pépin JL, Borel JC, Janssens JP. Obesity hypoventilation syndrome: an underdiagnosed and undertreated condition. Am J Respir Crit Care Med 2012:186:1205-7.

3 Mokhlesi B. Obesity hypoventilation syndrome: a state-of-the-art review. Respir Care 2010;55:1347-62.

4 Wang YC, McPherson K, Marsh T, et al. Health and economic burden of the projected obesity trends in the USA and the UK. Lancet 2011;378:815-25.

5 Norman RG, Goldring RM, Clain JM, et al. Transition from acute to chronic hypercapnia in patients with periodic breathing: predictions from a computer model. J Appl Physiol 2006;100:1733-41.

6 Mokhlesi B, Tulaimat A, Faibussowitsch I, et al. Obesity hypoventilation syndrome: prevalence and predictors in patients with obstructive sleep apnea. Sleep Breath 2007;11:117-24. 